\title{
The Challenging Dream of Rene Favaloro and Genesis of Saphenous Venous Grafts
}

\author{
Md. Anisuzzaman, Nazmul Hosain \\ Department of Cardiac Surgery, Chittagong Medical College, Chattogram
}

Key Words :

(Cardiovasc.j. 2020; 12(2): 149-153)

Favaloro, saphenous vein,

venous graft, $C A B G$.

\section{Introduction:}

Rene Geronimo Favaloro was a noble personality in the history of heart surgery. Though Known mostly in the surgeons' circles for the Favaloro sternal retractor named after him, his contribution in introducing saphenous venous coronary grafts have saved millions of lives over last six decades. By his admirable integrity, honesty, commitment to the patients, selflessness and compassion, Dr Favaloro has set an example that every surgeon should emulate. ${ }^{1}$ But this famous and talented surgeon ultimately had a very unfortunate and tragic end of his colorful life. Rene G Favaloro was born in 1923 and raised in La Plata, Argentina. After graduating from high school, he was admitted to the School of Medicine at the National University of La Plata. During his third year, he began his medical residency at the Hospital
Policlinico San Martin, a medical centre that received the most complicated cases from much of Buenos Aires province. In that residency program, he attended procedures carried out by Professors Jose Maria Mainetti and Federico E. B. Christmann, from whom he learned simplicity and standardization that he would later apply to his great contributions to cardiovascular operating techniques. Favaloro graduated with a medical degree in 1949..$^{2,3}$

After graduation, Favaloro was interested to join as a medical auxiliary but for that he needed to join Peronist Party first. He denied and moved instead to a small-town Jacinto Arauz in La Pampa Province as the town's doctor, when the resident doctor died. He joined then and brought his brother Juan Jose into the clinic (Fig 1A). He got married to Maria Antonia Delgado in $1951 .{ }^{4}$
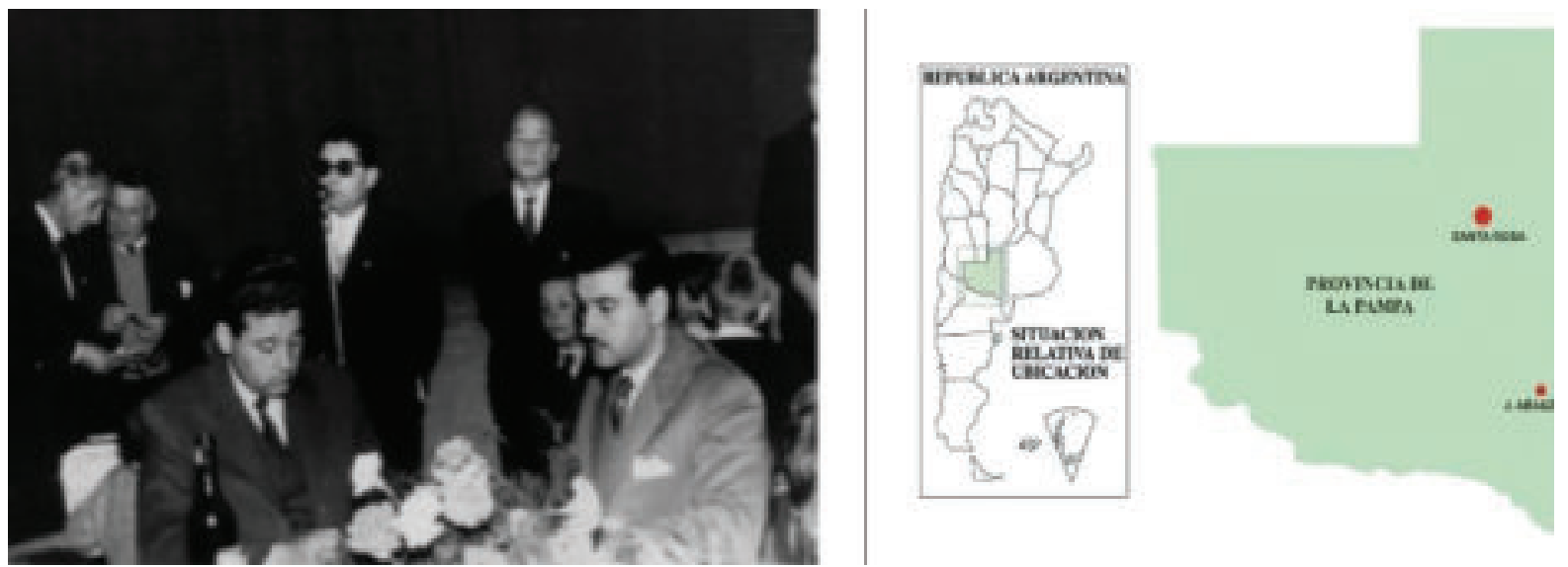

Fig.-1: A-Rene Favaloro with his brother Juan Jose \& B- The location of La Plata province in the Argentine map.

Address of Correspondence: Dr. Md Anisuzzaman, Department of Cardiac Surgery, Chittagong Medical College, Chattogram, Bangladesh. E-mail: aniscts10@gmail.com

- 2020 authors; licensed and published by International Society of Cardiovascular Ultrasound, Bangladesh Chapter and Bangladesh Society of Geriatric Cardiology. This is an Open Access article distributed under the terms of the CC BY NC 4.0 (https://creativecommons.org/licenses/by-nc/4.0). 
Favaloro and his brother endeavored to improve the general level of health in that remote area (Fig 1B). They trained and educated the general public, teachers, and nurses and improved health care delivery. They equipped the town with an operating room and X-ray. They also improved the laboratory, thereby providing essential surgical and diagnostic tools. ${ }^{4-5}$

While working in La Pampa, Favaloro became interested in cardiovascular intervention and developed an enthusiasm for thoracic surgery. Favaloro met Professor Mainetti, who suggested him to go to the famous Cleveland Clinic in USA. In the beginning, he had doubts about leaving his profession but thought that he could make a greater contribution to the community on returning from the United States. With few resources and rudimentary English, he decided to move to Cleveland. ${ }^{5,6}$

At first, he worked as a resident and later as a member of the operating team, working with Donald B. Effler, Head of Cardiovascular surgery, F. Mason Sones, Jr, who was in charge of the Angiography Laboratory, and William L. Pruodfit, the Head of the Department of Cardiology. Dr Donald Effler (Fig 2A) invited him to observe the work of the Department of Thoracic and Cardiovascular Surgery. Soon afterward, Dr Effler allowed Dr Favaloro to scrub and participate as a second assistant. He subsequently became regular operative assistant of Dr Effler and Dr Groves.
This entailed him participating in additional minor OT tasks like helping the anesthetists and the extracorporeal pump operators as well as removing the drains postoperatively. In short, he undertook a wide variety of supplementary tasks with the same degree of enthusiasm and physical stamina that he applied to all his activities. He then developed a long-lasting friendship with Dr Mason Sones, the father of coronary cineangiography, who taught him to read and interpret coronary and ventricular images (Fig 2B). ${ }^{6}$

His work involved valvular and congenital diseases in the beginning. Later on, he became interested in other areas. Having hardly finished work in operating room, Favaloro would spend hours and hours reviewing coronary angiograms and studying coronary arteries and their relation with the cardiac muscle. The laboratory of Soneshad the largest collection of angiograms then in the United States.

Favaloro began to consider the possibility of using the saphenous vein in coronary surgery. He put his ideas into practice for the first time in May 9, 1967. The basic principle was to bypass a diseased (obstructed) segment of a coronary artery in order to deliver blood flow distally (Fig 3). The standardization of this technique called coronary artery bypass surgery, was the work of his career, and ensured that his prestige would transcend the limit of his country. The procedure radically changed the treatment of coronary disease. In
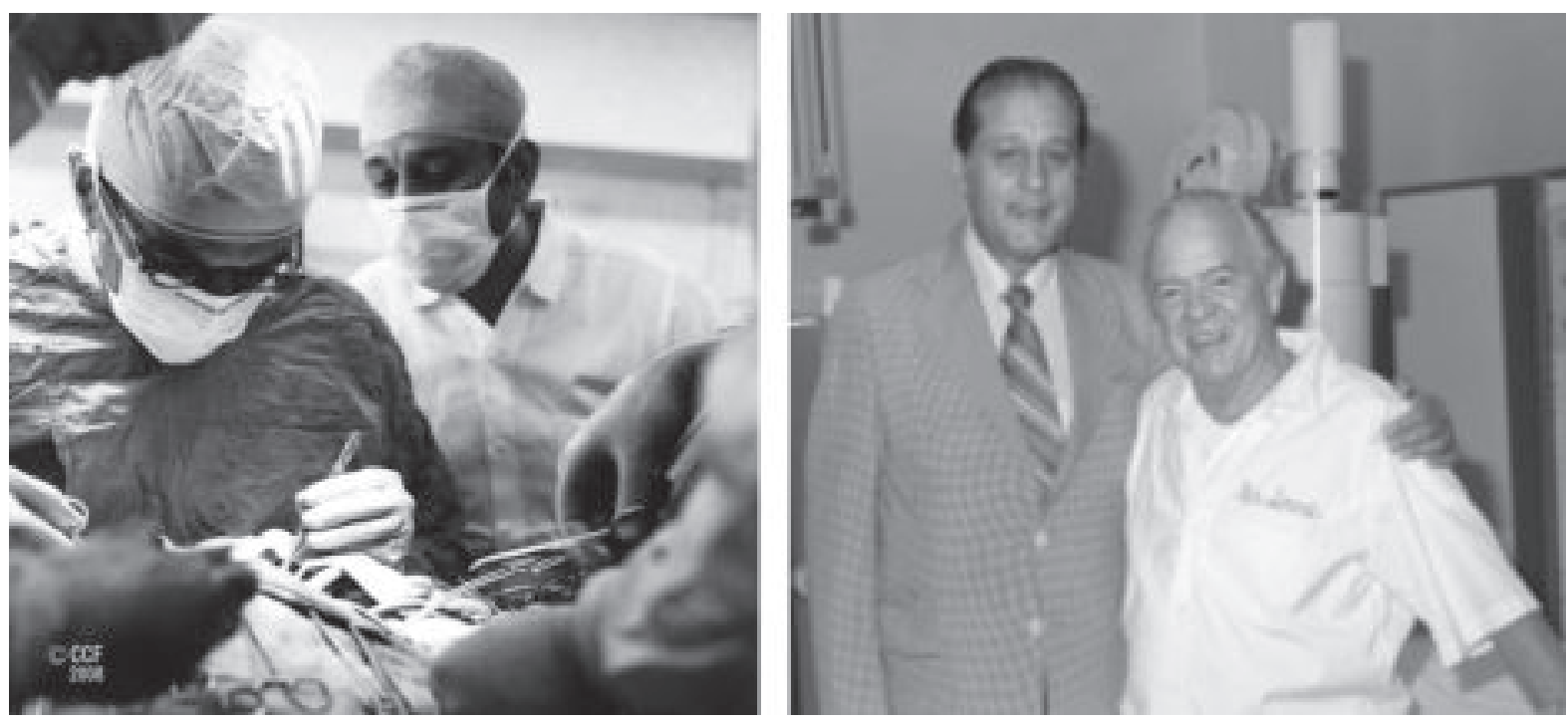

Fig.-2: A-Rene G Favaloro with Donald B-Effler and Rene G Favaloro with Masone Sones in Cleveland. 
1970, he published one of his best-known books, Surgical Treatment of Coronary Arteriosclerosis. ${ }^{7}$

Favaloro returned to Argentina in 1971 with the dream of developing a center of excellence similar to the Cleveland Clinic that combined medical treatment, research and education. He founded the Fundacion Favaloro in 1975 along with several collaborators. He took pride in having trained more than 450 residents from all over Argentina and Americas. Favaloro contributed to raise the standard level of his specialty for the benefit of patients through innumerable coursers, seminars, and conferences organized by the Foundacion, among them the distinguished "Cardiology for the Consultant" (Cardiologia para el Consultante), held every two years.

In 1980, Favaloro established the "Basic Investigation Laboratory" (Laboratorio de Investigacion Basica), which was long financed with his own money and which at the time, depended upon the support of the Research and Teaching Department of the Fundacion Favaloro. Subsequently, it was transformed into the Universidad Favaloro in August 1998.

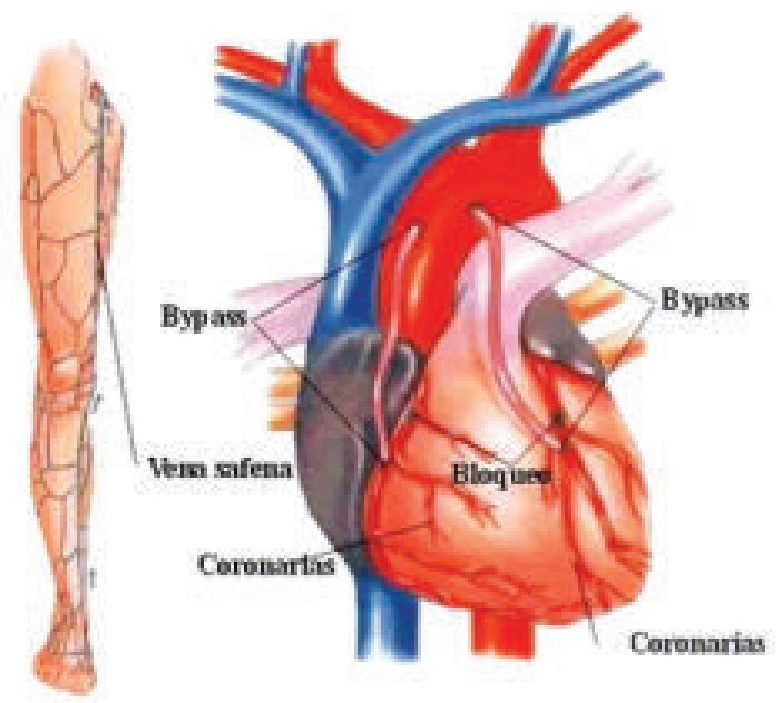

Fig.-3: Favaloro's principle of using the saphenous vein in coronary surgery.

In 1992, the nonprofit Favaloro Foundation Institute of Cardiology and Cardiovascular Surgery opened in Buenos Aires. With the motto "advanced technology in the service of medical humanism", this institute offers highly specialized services of cardiology, cardiovascular surgery and heart, lung, cardiopulmonary, liver, kidney, and bone marrow transplants among other areas. Favaloro focused his career there, surrounded by a selected group of professionals. It should be mentioned, however that, despite the immense cost of bypass surgery, Dr. Favaloro operated daily on indigent patients, something that he felt was both a necessity and his obligation.

He kept his emphasis on disease prevention and promoting basic rule of hygiene to reduce mortality rate. With that objective, the Fundacion Favaloro researches illness detection and prevention programs. Also, many publications were released by the publishing center of the Favaloro Foundation, which ceased to operate in 2000. The Favaloro Foundation is currently one of the largest institutions dedicated to cardiology in the Americas.

Argentina was submerged in an economic and political crisis and the Favaloro Foundation was then US\$ 18 million in debt. Favaloro tried to draw the attention of Argentine government to aid the Foundation, but never received an official response, nor would the director of the PAMI (public agency of medical insurance) to pay the agency's debt to the Foundation. On July 29, 2000, at the age of 77 , Favaloro committed suicide by shooting himself in the chest, ${ }^{7}$ the most unfortunate thing a thoracic surgeon could have possibly done!

Favaloro was an active member of 26 societies, corresponding of 4 , and honorary of 43 . He received innumerable international distinctions. These include John Scott Prize 1979, granted by Philadelphia; the creation of the Chair of Cardiovascular Surgery "Dr Rene G Favaloro" Tel Aviv University, Israel, 1980); the distinction of the Fundacion Conchita Rabago de Gimenez Diaz (Madrid, Spain, 1982); the Teacher Prize of Argentinian Medicine(1986); the distinguished Alumnus Award of the Cleveland Clinic Foundation(1987); The Gairdner Foundation International Award, granted by the Gairdner Foundation (Toronto, Canada, 1987); the Rene Leriche Prize 1989, granted by the International Surgery Society; the Gifted Teacher Award, granted by the American College of Cardiology(1992); the Golden Plate Award of the American Academy of Achievement (1993); the 

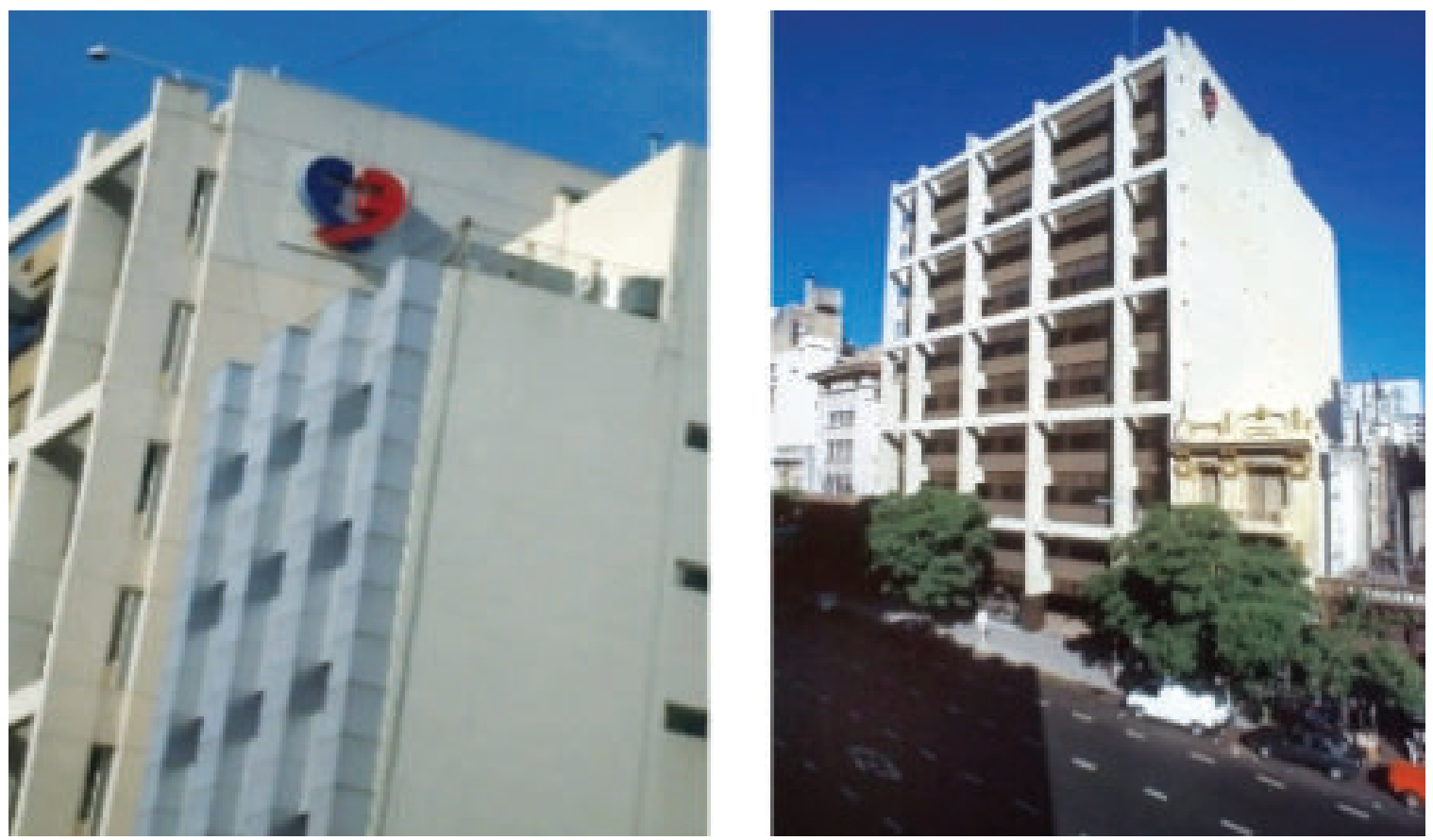

Fig.-4: Favaloro Foundation, Argentina.

Diamond Konex Award as the most important scientist in the last decade in his country (Argentina, 1993); and the Prince Mahidol Award, granted by His Majesty the King of Thailand( Bangkok, Thailand, 1999). In 2007, he was named the second greatest Argentine of all time, on the TV show El Gen Argentino. On July 12, 2019, Google showed a Doodle celebrating what would have been his $96^{\text {th }}$ birthday.

Favaloro participated in education programming for the public, distinguishing himself in the television series The Great Medical Themes, and in numerous conferences in Argentina and throughout the world on topics such as education, medicine and modern society. He was also mentioned in the documentary movie Forks over Knives.

Rene G Favaloro published more than 300 works in his specialty. Owing to his passion for history, he also wrote two books about General Jose de san Martin. The few important works are belowSurgical Treatment of Coronary Arteriosclerosis (1970), Recuerdos de un medico rural ("Memories of a rural doctor", 1980), Conoce usted a San Martin? ("Do you know San Martin", 1986), La Memoria de Guayaquil ("The memory of
Guayaquil" 199), De La Pampa a los Estados Unidos ("From La Pampa to the United States",1993), Don Pedro y la Educacion (Don Pedro and Education", 1994) $)^{2,8}$

Many surgeons contributed to the development of coronary artery bypass grafting procedure. As it often happens in medicine, a personal success is, more often than not, the result of teamwork and, as a rule, relies on the preceding pioneering work of others. That's why Favaloro said, "I believe in teamwork, 'we' is more important than 'I'. In Medicine, evolution comes from the efforts of many accumulated over the years." Despite all his achievements it's a pity that one of the greatest chest surgeons of all time ultimately had to commit suicide shooting at his own chest. But Rene Favaloro would always be remembered for his contribution in the introduction of saphenous venous grafts in coronary bypass surgery.

\section{Conflict of Interest - None.}

\section{References:}

1. Konstantinov IE. Rene Favaloro and the fatherhood of the coronary bypass operation: Lest we forget. $J$ Thorac Cardiovasc Surg 2019;157(1):196-198. 
2. Larocca, Bruno (2013-06-13). "El caso del Dr. Favaloro"[The case of Dr. Favaloro]. Gatopardo (in Spanish). Retrieved 2019-07-12.

3. "Rene Favaloro: A pioneer in heart bypass surgery". Aljazeera.com. Retrived 12 July 2019.

4. Krauss, Clofford (August 7, 2000). "Argentina Searches Its Soul Over a Suicide". The New York Times. Retrieved 15 June 2009

5. Rene Favaloro's $96^{\text {th }}$ birthday. Google.com. 12 July 2019.
6. Cooley DA. In memoriam. Tribute to Rene' Favaloro, pioneer of coronary bypass. Tex Heart Inst J 2000; 27: 231-232.

7. Konstatinov IE. The first coronary artery bypass operation and forgotten pioneers. Ann Thorac Surg 1997; 64: 1522-1523.

8. Bakaeen FG, Blackstone EH, Pettersson GB, Gillinov AM, Svensson LG. The father of coronary artery bypass grafting: Rene Favaloro and the $50^{\text {th }}$ anniversary of coronary artery bypass grafting. $J$ Thorac Cardiovasc Surg 2019; 55: 2324-2328. 